\title{
COVID-19 en la República Dominicana: Declaramos la guerra, Pero... ¿ESTAmos ganando?
}

\author{
Vicente L. de Peña Peralta ${ }^{a}$, Raúl Ovalle Marte ${ }^{\mathrm{b}}$ \\ y Francisco A. Ramírez de León ${ }^{c}$
}

Received: 1/5/2020 Approved: 15/7/2020

Cómo citar: de Peńa Peralta, V. L., Ovalle Marte, R., \& Ramírez de León, F. A. (2020). COVID-19 en la República Dominicana: Declaramos la guerra, pero. ¿estamos ganando? Ciencia, Economía y Negocios, 4(2), 51-74. Doi: https://doi.org/10.22206/ceyn.2020.v4i2.pp51-74

\begin{abstract}
Resumen
En este documento se presentan estimaciones de la tasa de contagio y el numero reproductivo $R_{0}$ del COVID-19 para la República Dominicana, contrastándolas con las identificadas para una selección de paises. Las estimaciones se obtienen adaptando el enfoque estado-espacio al modelo canónico de epidemiología SIR. Con datos obtenidos al 16 de abril, los resultados indican una tendencia decreciente en los contagios secundarios $\left(R_{0}\right)$, sugiriendo que las politicas de distanciamiento han sido efectivas en disminuir la propagación del virus. Sin embargo, también sugieren que para reducirla a los niveles prevalecientes en los paises que han sido más exitosos conteniendo la epidemia se deberían fortalecer y extender las medidas vigentes.
\end{abstract}

Palabras clave: SIR; epidemiología; espacio estado; filtro de Kalman; tasa de contagio.

Códigos JEL: E1, H0, I1

\footnotetext{
a Departamento de Economía, Universidad Autónoma de Santo Domingo, Santo Domingo, República Dominicana. Correo-e: vicenteluis9@gmail.com

b Departamento de Economía, Pontificia Universidad Católica Madre y Maestra, Santo Domingo, República Dominicana. Correo-e: raulovalle@gmail.com

c Departamento de Economía, Universidad Autónoma de Santo Domingo y Pontificia Universidad Católica de Santo Domingo, Santo Domingo, República Dominicana.

Correo-e: eard10783@gmail.com
}

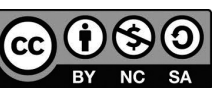

Esta obra está bajo licencia internacional Creative Commons Atribución-NoComercial-CompartirIgual 4.0 Internacional 
COVID-19 in THE DoMinican RePUblic:

WE DECLARED WAR, BUT... ¿AARE WE WINNING?

\title{
Vicente L. de Peña Peralta, Raúl Ovalle Marte and Francisco A. Ramírez de León
}

\author{
Received: 1/5/2020 Approved: 15/7/2020
}

\begin{abstract}
This document presents estimates of the contagion rate and the reproductive number $R_{0}$ of COVID-19 for the Dominican Republic, contrasting them with those identified in other countries. To estimate the model, we adapt the state-space framework to the canonical SIR epidemiology model. With data obtained as of April 16, 2020, the results indicate a decreasing trend in secondary infections (RO), suggesting that distancing policies have been effective in reducing the spread of the virus. However, in order to reduce the actual levels in secondary infections to the levels of those countries that have been most successful in containing the epidemic, the results also suggest that existing measures should be strengthened and extended.
\end{abstract}

Keywords: SIR; epidemiology; state space; Kalman filter; contagion rate.

JEL Codes: E1, H0, I1 


\section{Introducción}

El riesgo de propagación indiscriminada del COVID-19 es el principal desafío que enfrentan las autoridades gubernamentales, los líderes del sector privado y la ciudadanía en general, a nivel global, incluyendo la República Dominicana, debido a las consecuencias humanitarias y económicas que esto acarrea.

Con el objetivo de analizar la evolución de la pandemia, tanto en términos de su tamaño final y el momento en que alcanza su pico, como de las condiciones bajo las cuales se disipa, hacedores de política e investigadores en todas partes del mundo emplean modelos que les permitan caracterizarla.

Este documento contribuye a esa discusión proponiendo una adecuación al modelo canónico usado en epidemiología (SIR), adaptando el enfoque de estado-espacio usado regularmente en el ámbito de las proyecciones econométricas. Esto, en sí mismo, no es una novedad en términos metodológicos (Sebastian \& Victor, 2017) y (Eksin et al., 2019), pero sí lo es en cuanto a su aplicación, dado que se emplea para diagnosticar la dinámica del COVID-19 en la República Dominicana, contrastándola con la de una selección de países.

Evaluando la tendencia del número básico de reproducción $\left(R_{0}\right)$ del virus, esto es, la cantidad de contagios adicionales que provoca un infectado nuevo, se concluye que tanto en la República Dominicana como en los países evaluados, las políticas de distanciamiento han reducido la propagación del virus. En el caso dominicano, estas pasaron de un promedio de nueve contagios secundarios, previo a la adopción de las medidas, a un número de dos, posterior a estas.

Las decisiones que adopten las autoridades en las próximas semanas, así como la conducta de la población en general, determinarán si el $R_{0}$ continuará su ritmo decreciente, resultando en un menor número de vidas afectadas, o revertirá su tendencia.

Las estimaciones hechas al 16 de abril de 2020 sugieren que, de continuar su tendencia decreciente, si se estabilizara alrededor del valor de uno (1) durante los próximos 30 días, como ha ocurrido en China y Corea del Sur, el máximo nivel de contagios rondaría los 13,500, en 
tanto el mayor nivel de nuevos infectados semanales sucedería hacia finales de abril, alcanzando un tope cercano a los 1,700 casos.

Si por el contrario, se quiebra la tendencia y $R_{0}$ se estabiliza en los niveles actuales, la pandemia se propagaría lo suficiente para infectar a alrededor del $7 \%$ de la población dominicana, en tanto el máximo nivel de contagios semanales ocurriría hacia septiembre de 2020 y nos aproximaríamos a los 51,000 casos, lo que evidencia la necesidad de extender y fortalecer las políticas de distanciamiento social.

El resto del documento se organiza como sigue: en la sección 2 se presenta el marco metodológico propuesto, especificando la representación estado-espacio en el modelo epidemiológico SIR. En la sección 3 se analizan los datos utilizados; en tanto, en la sección 4 se presentan los resultados. Finalmente, en la sección 5 se concluye.

\section{Metodología}

Para caracterizar la evolución de la epidemia ocuparemos el modelo canónico usado en epidemiología (Kermack \& McKendrick, 1927), aplicado para el estudio de la evolución del COVID-19 en República Dominicana por De Peña \& Ramírez (2020), mejor conocido como SIR. Bajo este marco, la población $(N)$ en riesgo de contraer una enfermedad contagiosa se divide en tres grupos: susceptibles $\left(S_{t}\right)$, infectados $\left(I^{t}\right)$ y removidos $(R)$.

Los susceptibles son personas no inmunes al virus, que aún no han entrado en contacto con infectados, pero se contagian al hacerlo. Los infectados son ex-susceptibles que habiendo interactuado con contagiados contrajeron el virus y, por tanto, son capaces de transmitirlo. Los removidos son ex-infectados que contrajeron el virus pero no son capaces de transmitirlo, ya sea porque adquirieron inmunidad tras recuperarse o fallecieron a causa de este.

Por simplicidad, el modelo no considera crecimiento poblacional (i.e.: $N=S_{t}+I_{t}+R$ ); supone que el período de incubación del agente infeccioso es instantáneo (i.e.: los síntomas se manifiestan a partir del contagio) y asume que el período de contagio es igual al de la duración de la enfermedad (i.e.: los contagiados pueden transmitirlo hasta tanto se recuperen). 
Bajo estos supuestos, la dinámica del modelo suele ilustrarse con el siguiente esquema (véase figura 1), que muestra que los susceptibles transicionan al grupo de infectados según la velocidad de contagio de la enfermedad, capturada por el parámetro $\beta$; en tanto, los infectados transicionan al grupo de removidos según la duración de la enfermedad, reflejada en el parámetro $\gamma$.

Figura 1. Esquema del modelo SIR básico

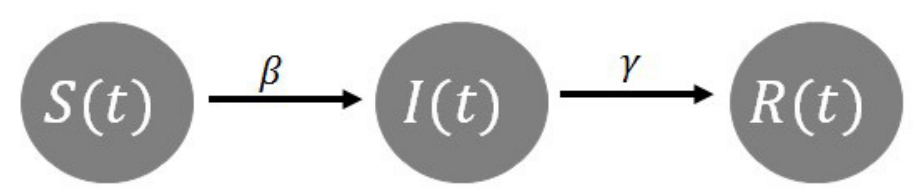

Fuente: elaboración propia.

Estas dinámicas se pueden representar a través del siguiente sistema de ecuaciones diferenciales representado:

$$
\begin{gathered}
\frac{\partial S_{t}}{\partial t}=-\beta S_{t} I_{t} \\
\frac{\partial I_{t}}{\partial t}=\beta I_{t} S_{t}-\gamma I_{t} \\
\frac{\partial R_{t}}{\partial t}=\gamma I_{t}
\end{gathered}
$$

donde $\beta$ se refiere a la tasa efectiva de contacto, definida como la probabilidad de que el contacto entre un individuo susceptible y un infectado resulte en contagio, en tanto $\gamma$ corresponde a la tasa de crecimiento de la población removida ${ }^{1}$.

$1 \beta$ recoge la combinación de la cantidad de interacciones ocurridas entre toda la población más el grado de transmisibilidad del virus; mientras que $\gamma$ se define como el inverso del período de incubación del virus. 
La ecuación 1 muestra que, asumiendo que todos los individuos tienen la misma probabilidad de contagiarse ${ }^{2}$, la variación del número de susceptibles es inversa a la tasa efectiva de contacto. En la ecuación 2 se observa que la variación del número de infectados aumenta con la cantidad de susceptibles que se contagian $\left(\beta S t I_{t}\right)$ y decrece en la medida que son removidos $(-\lambda I)$. Finalmente, la ecuación 3 captura los infectados que pasan a ser removidos y dejan de incidir en el desarrollo de la epidemia, ya sea porque se recuperaron y adquirieron inmunidad o porque fallecieron.

Una vez definidas las condiciones iniciales del modelo ${ }^{3}$ más los parámetros $\beta$ y $\gamma$, podremos cuantificar el número de susceptibles, infectados y removidos en cada momento del tiempo, lo que permitirá caracterizar la epidemia en términos de su tamaño final ${ }^{4}$, el momento en que alcanza su pico y bajo cuáles condiciones se disipa. Nótese que podemos reescribir (E2) en términos de la tasa de crecimiento de los infectados $\left(\frac{\frac{\partial t_{t}}{\partial t}}{t_{t}}=(\beta S-\gamma)\right)$ y así establecer que la epidemia se disipará (i.e.: $\frac{\partial I_{t}}{\partial t} \leq 0$ ) siempre que $\frac{\beta S}{\gamma}<1$, y se expandirá en caso contrario. En epidemiología, esta última expresión se conoce como número básico de reproducción $\left(R_{0}=\frac{\beta S}{\gamma}\right)$, y refleja el número promedio de contagios secundarios generados por un caso de contagio nuevo en una población susceptible, durante un período infeccioso (Dietz, 1993).

$R_{0}$ es la variable más importante de calcular y monitorear durante un brote infeccioso. Recoge tres elementos fundamentales de la evolución de una epidemia: la duración del contagio, el grado de transmisibilidad de la enfermedad y la tasa de contacto entre sujetos de la población susceptible. Dado que las dos primeras son características inherentes al patógeno, los esfuerzos de las autoridades para mitigar la

\footnotetext{
2 Esto se conoce como Ley de Masas e implica que la incidencia de una epidemia depende directamente del producto del número de individuos infectados por el número de susceptibles (Ross and Thomson, 1910).

3 Para esto, supondremos que la epidemia inicia con un determinado número de infectados $\left(I(0)=I_{0}\right)$, que aún no se recuperan ni fallecen (i.e.: $R_{0}=0$ ), lo que define el número inicial de susceptibles como $S_{0}=N-I_{0}$

4 Esto se refiere a la cantidad total de infectados durante el transcurso de la epidemia, también conocido como la tasa de ataque en el campo de la epidemiología aplicada y suele expresarse como \% de la población analizada.
} 
propagación del virus suelen enfocarse en alterar patrones de contacto entre individuos implementando medidas de distanciamiento social, como toques de queda o cierres de escuelas y negocios ${ }^{5}$. Esto último implica que la tasa efectiva de contacto, $\beta$, en lugar de ser constante, podría variar en el tiempo $(\beta)$ producto de las intervenciones de las autoridades y, en consecuencia, también $R_{0}^{6}$.

Partiendo de lo anterior, para capturar de forma más precisa la dinámica de las epidemias ante episodios de intervenciones que alteren la conducta social de los individuos, emplearemos $R_{t}$ o el número efectivo de reproducción. Liu et al. (2018) señalan que, ante estimaciones confiables de $\gamma$, el análisis Bayesiano de $\beta_{t}$ y $R_{t}$ se constituye como una herramienta útil a la hora de analizar la dinámica de las pandemias.

\subsection{Modelo espacio-estado}

El modelo espacio-estado se especifica usando la ecuación dinámica de los infectados $(I(t))$, (ecuación E2) en tiempo discreto del modelo SIR presentado y, a diferencia de este modelo, se trata como variable de estado a la tasa de contagio $\left(\beta_{t}\right)$, es decir, un parámetro cambiante. La especificación es la siguiente:

$$
\begin{gathered}
\Delta I_{t}=\beta_{t} I_{t-1}-\gamma I_{t-1} \\
\beta_{t}=\beta_{t-1}+\varepsilon_{t} \\
E_{t}\left(\varepsilon_{t}\right)=0 \quad \operatorname{var}\left(\varepsilon_{t}\right)=\sigma^{2}
\end{gathered}
$$

donde la primera expresión es la ecuación de observación, la cual asume que no hay error de medición. Mientras que la segunda es la

\footnotetext{
5 En rigor existen ejemplos de medidas no asociadas a limitar patrones de contactos, sino el grado de transmisibilidad del virus, como las campañas educativas de uso de preservativos en el caso del VIH o la de aumentar la frecuencia de lavado de manos en el caso del COVID-19.
}

6 Véase Delamater et al. (2019). 
ecuación de estado que caracteriza la dinámica de la tasa de contagio. El supuesto de que $\beta_{t}$ es un parámetro cambiante permite una especificación más flexible del modelo SIR y considera el hecho de que este es incidido por la probabilidad de contagio y la interacción humana. Este último factor es impactado por el efecto de las políticas de distanciamiento y otras medidas que limitan la exposición al virus.

\section{Datos}

Para llevar a cabo la estrategia descrita en la sección anterior se utilizan tres fuentes de datos. La primera de ellas es el número diario de infectados, tanto los acumulados (véase figura 2) como los nuevos (véase figura 3), obtenidos de la base de datos de la web del Centro de Ciencias de Sistemas e Ingeniería de la Universidad Johns Hopkins? Estas series se utilizan para estimar la tasa de contagio y a partir de los parámetros de transmisión para República Dominicana y un conjunto de países.

Figura 2. Casos acumulados diarios de COVID-19 para países seleccionados (del 22 de enero al 16 de abril de 2020)

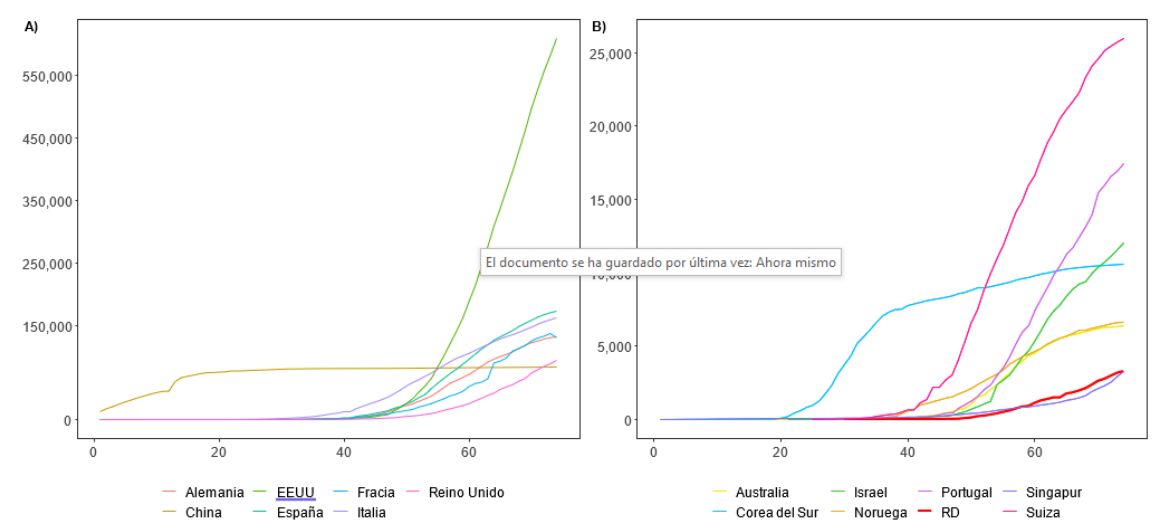

Fuente: elaboración propia basada en datos de joachim-gassen/tidycovid19”.

7 https://coronavirus.jhu.edu/map.html 
Figura 3. Casos nuevos diarios de COVID-19 para países seleccionados (del 22 de enero al 16 de abril de 2020)
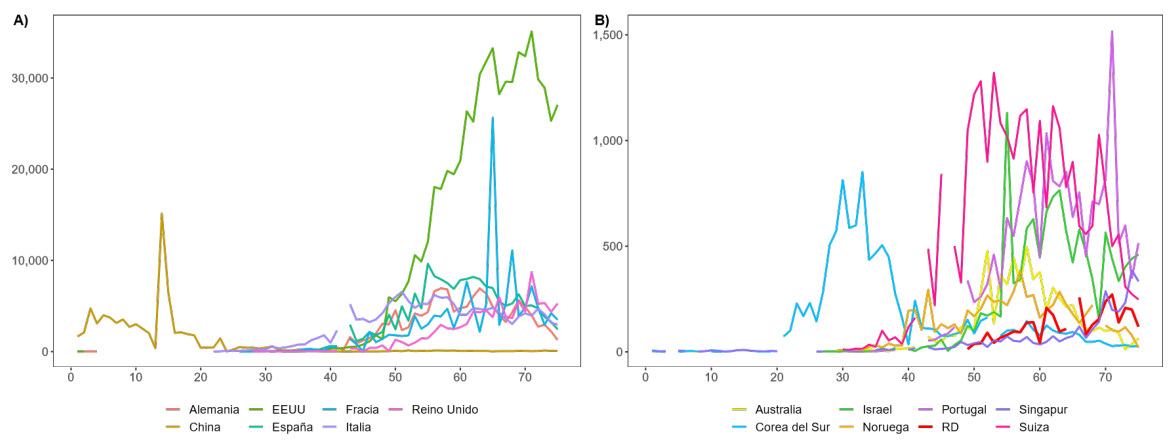

Fuente: elaboración propia con datos de joachim-gassen/tidycovid19”.

China y Corea del Sur son seleccionados debido a que se encuentran en una fase avanzada de la curva, mientras que Alemania, España, Francia e Italia, a la fecha de la publicación de este documento, se encontraban en la etapa intermedia, cerca de lo que sería un punto de inflexión. Por su parte, Estados Unidos es el caso de un país donde el virus se encuentra en el momento crítico de propagación. La selección de los restantes obedece, al igual que los anteriores, a que se constituyen como los países líderes en realización de pruebas a sus habitantes, garantizando una mejor caracterización de la evolución de la pandemia.

La segunda fuente es la base de datos desarrollada por Joachim Gassem ${ }^{8}$ para el estudio de la pandemia, de la cual se extraen datos de patrones de movilidad publicados por Google. En la tabla 1 se resume esta información para los países en cuestión. La tercera fuente corresponde a las publicaciones oficiales de fechas en las que se adoptaron medidas de restricción de circulación, ya sean parciales o totales, en los países seleccionados.

Por último, las condiciones iniciales del modelo asumen una población $N=10$ millones de personas, una tasa de recuperación

8 Esta base de datos es parte del paquete tidycovid19 del programa de análisis estadísticos $\mathrm{R}$ Studio joachim-gassen/tidycovid19. 
$\gamma=1 / 14^{9}$ y un primer infectado al 1ro de marzo de 2020. Los valores de los parámetros $\beta_{\mathrm{t}}$ se establecen utilizando la metodología descrita en la sección 2.1. La simulación se ejecuta hasta el 31 de diciembre de 2020 .

Tabla 1. Patrones de movilidad en países seleccionados del 3 enero al 15 de abril de 2020

\begin{tabular}{|c|c|c|c|c|c|c|c|}
\hline \multirow[b]{2}{*}{ Países } & \multicolumn{6}{|c|}{ Sectores } & \multirow{2}{*}{$\begin{array}{c}\text { Cuarentena total o } \\
\text { parcial }\end{array}$} \\
\hline & $\begin{array}{l}\text { Comercio } \\
\text { y recreo }\end{array}$ & $\begin{array}{l}\text { Farmacia y } \\
\text { comestibles }\end{array}$ & Parques & Transporte & Trabajo & Residencias & \\
\hline $\begin{array}{l}\text { Rep. } \\
\text { Dom. }\end{array}$ & $-78 \%$ & $-58 \%$ & $-69 \%$ & $-85 \%$ & $-67 \%$ & $20 \%$ & 20 y 27 de marzo \\
\hline Alemania & $-56 \%$ & $0 \%$ & $35 \%$ & $-48 \%$ & $-29 \%$ & $10 \%$ & $\begin{array}{l}20 \text { de marzo } \\
\text { y } 9 \text { de abril }\end{array}$ \\
\hline Australia & $-40 \%$ & $-18 \%$ & $-51 \%$ & $-63 \%$ & $-41 \%$ & $18 \%$ & 23 de marzo \\
\hline Austria & $-88 \%$ & $-62 \%$ & $-76 \%$ & $-2 \%$ & $-62 \%$ & $-70 \%$ & No tiene \\
\hline Bélgica & $-79 \%$ & $-25 \%$ & $-20 \%$ & $-60 \%$ & $-47 \%$ & $20 \%$ & 43,907 \\
\hline China & n.a. & n.a. & n.a. & n.a. & n.a. & n.a. & 23 de enero \\
\hline $\begin{array}{c}\text { Corea del } \\
\text { Sur }\end{array}$ & $-16 \%$ & $10 \%$ & $17 \%$ & $-13 \%$ & $-7 \%$ & $6 \%$ & No tiene \\
\hline EE. UU. & $-45 \%$ & $-7 \%$ & $-16 \%$ & $-49 \%$ & $-38 \%$ & $14 \%$ & 23 de marzo \\
\hline España & $-92 \%$ & $-44 \%$ & $-85 \%$ & $-84 \%$ & $-63 \%$ & $26 \%$ & 14 de marzo \\
\hline Francia & $-86 \%$ & $-39 \%$ & $-74 \%$ & $-79 \%$ & $-55 \%$ & $23 \%$ & 16 de marzo \\
\hline Israel & $-89 \%$ & $-37 \%$ & $-74 \%$ & $-59 \%$ & $-45 \%$ & $16 \%$ & 19 de marzo \\
\hline Italia & $-86 \%$ & $-42 \%$ & $-83 \%$ & $-78 \%$ & $-62 \%$ & $26 \%$ & 10 de marzo \\
\hline Noruega & $-43 \%$ & $-2 \%$ & $-2 \%$ & $-55 \%$ & $-36 \%$ & $9 \%$ & 12 de marzo \\
\hline Portugal & $-78 \%$ & $-40 \%$ & $-73 \%$ & $-77 \%$ & $-58 \%$ & $26 \%$ & No tiene \\
\hline $\begin{array}{l}\text { Reino } \\
\text { Unido }\end{array}$ & $-81 \%$ & $-32 \%$ & $-37 \%$ & $-70 \%$ & $-57 \%$ & $19 \%$ & 23 de marzo \\
\hline Singapur & $-61 \%$ & $-21 \%$ & $-51 \%$ & $-66 \%$ & $-51 \%$ & $32 \%$ & 7 de abril \\
\hline Suiza & $-77 \%$ & $11 \%$ & $27 \%$ & $-47 \%$ & $-41 \%$ & $15 \%$ & No tiene \\
\hline
\end{tabular}

Fuente: elaboración propia con datos de joachim-gassen/tidycovid19”.

9 La Organización Mundial de la Salud (OMS) indica que el período de incubación máximo del virus es de 14 días; visitar la página https://www.who.int/news-room/q-a-detail/q-a-coronaviruses. 


\section{Resultados}

Utilizando los datos de contagios por COVID-19 en la República Dominicana y en un grupo de países seleccionados ${ }^{10}$, se estiman las tasas efectivas de contacto $(\beta)$ y el correspondiente número de contagios secundarios $(R)$, con el fin de evaluar la efectividad de las políticas de distanciamiento social a la hora de mitigar la propagación del virus.

En la figura 4 se muestra la evolución de $\beta_{t}$ y $R_{t}$ en la República Dominicana a partir de la detección del primer contagio y, adicionalmente, se presentan datos de la variación de visitas en lugares comúnmente frecuentados por la población ${ }^{11}$.

Figura 4. Trayectoria de $\beta, R_{0}$ en la República Dominicana (del 16 de marzo al 15 de abril de 2020)
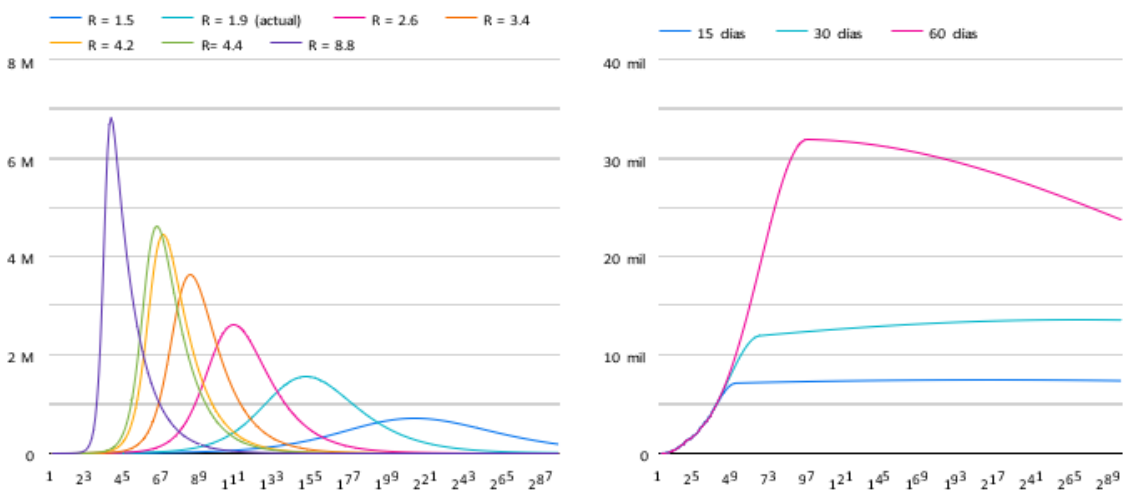

Fuente: elaboración propia.

Los resultados reflejan una tendencia decreciente de la tasa efectiva de contacto y, por consiguiente, del grado de propagación del virus. Dicha dinámica se aprecia aún previo a la adopción de medidas gubernamentales, posiblemente reflejando conductas de autoaislamiento adoptadas por las personas, lo que se acentúa a partir de la

10 Selección basada en países líderes de ranking global en pruebas suministradas per cápita.

11 El mismo ejercicio se replica para el resto de los países en el anexo A. 
implementación de las diversas políticas de distanciamiento aplicadas por las autoridades.

En el caso de República Dominicana, la reducción en la tasa de contacto alcanza el $77 \%$, consistente con la caída observada en los datos de movilidad de Google (véase tabla 1) y superando los declives observados en Estados Unidos, Francia y Singapur, lo que permitió reducir el promedio de contagios secundarios por semana de un máximo de nueve contagios, previo a la implementación de las medidas, a dos contagios, posterior a dicha implementación.

Tabla 2. Evolución $R_{0}$ a partir de medidas distanciamiento social* (días)

\begin{tabular}{|c|c|c|c|c|c|c|c|}
\hline \multirow{2}{*}{ País } & \multicolumn{7}{|c|}{$R_{0}$} \\
\cline { 2 - 8 } & $\begin{array}{c}\text { Días trans- } \\
\text { curridos a } \\
\text { partir de } \\
\text { medidas }\end{array}$ & $\begin{array}{c}\text { Días } \\
\text { requeridos } \\
\text { para } \\
R<1,4\end{array}$ & $\begin{array}{c}{[\mathbf{1 . 0}-} \\
\mathbf{1 . 4}]\end{array}$ & $\begin{array}{c}{[\mathbf{1 . 5}-} \\
\mathbf{1 . 9}]\end{array}$ & $\begin{array}{c}{[\mathbf{2 . 0}-} \\
\mathbf{2 . 4}\end{array}$ & $\begin{array}{c}{[\mathbf{2 . 5}-} \\
\mathbf{3 . 0}\end{array}$ & $\mathbf{> 3}$ \\
\hline Rep. Dom. & 23 & - & 0 & 0 & 7 & 3 & 13 \\
\hline China & 76 & 23 & 54 & 0 & 7 & 4 & 11 \\
\hline Alemania & 43 & - & 3 & 5 & 4 & 4 & 27 \\
\hline Australia & 24 & 16 & 9 & 2 & 1 & 3 & 9 \\
\hline Austria & 40 & 34 & 7 & 5 & 2 & 2 & 24 \\
\hline Bélgica & 38 & - & 0 & 3 & 6 & 2 & 27 \\
\hline Corea del Sur & 76 & 16 & 38 & 5 & 5 & 3 & 25 \\
\hline Espańa & 43 & 40 & 3 & 5 & 4 & 3 & 28 \\
\hline Estados Unidos & 45 & - & 0 & 3 & 2 & 6 & 34 \\
\hline Francia & 44 & - & 0 & 0 & 6 & 10 & 28 \\
\hline Hong Kong & 75 & 23 & 15 & 26 & 9 & 20 & 5 \\
\hline Israel & 43 & - & 0 & 6 & 2 & 3 & 32 \\
\hline Italia & 47 & 43 & 3 & 12 & 4 & 5 & 23 \\
\hline Noruega & 41 & 37 & 5 & 8 & 11 & 1 & 16 \\
\hline Portugal & 36 & - & 0 & 4 & 5 & 2 & 25 \\
\hline Singapur & 74 & 23 & 12 & 17 & 28 & 9 & 8 \\
\hline Suiza & 40 & 34 & 3 & 9 & 4 & 2 & 22 \\
\hline & & & & & & & \\
\hline
\end{tabular}

Fuente: elaboración propia basada en media móvil -5 días de $R_{0}$. Datos vigentes al 16 de abril de 2020 . 
Del resto de los países evaluados, Italia, Corea del Sur y Noruega lograron la mayor disminución en sus tasas de contacto, con caídas de al menos un $90 \%$ desde sus niveles picos hasta la fecha, lo que contribuyó a que el número de contagios secundarios de la última semana se ubique por debajo del 1.4, inferior al rango mínimo estimado por la OMS para el COVID-19 ${ }^{12}$. A este logro se suman Australia, Austria, China y Hong Kong.

Una forma alternativa de evaluar el impacto de las medidas de las autoridades es analizar el tiempo que requirió cada país en reducir $R_{0}$ a los niveles actuales (véase tabla 2). En la tabla se aprecia que a partir de la adopción de las medidas de distanciamiento, la República Dominicana requirió 13 días para reducir los contagios secundarios a menos de tres, lo que se compara favorablemente con el resto de los países evaluados y dista de los 34 días requeridos por Estados Unidos, el mayor tiempo entre los países evaluados.

De los países que redujeron sus contagios secundarios a menos de 1.4, Italia y España (epicentro europeo de la pandemia) fueron los que requirieron más tiempo para hacerlo (43 y 40 días, respectivamente); en tanto Australia y Corea del Sur solo necesitaron 16 días, los más rápidos en hacerlo.

Tabla 3. Contagios totales según distintos escenarios número de reproducción $\mathrm{R}_{0}$ (en miles)

\begin{tabular}{|c|c|c|c|c|c|c|c|c|c|c|}
\hline \multicolumn{9}{|c|}{$R_{0}$ efectivo entre 03/03/2020 - 16/04/2020* } & \multicolumn{3}{c|}{ Escenarios convergencia a } \\
\hline Fecha & 8.78 & 4.43 & 4.23 & 3.42 & 2.62 & 1.94 & 1.54 & 60 días & 30 días & 15 días \\
\hline $16 / 3 / 2020$ & 0 & 0 & 0 & 0 & 0 & 0 & 0 & 0 & 0 & 0 \\
\hline $21 / 3 / 2020$ & 0 & 0 & 0 & 0 & 0 & 0 & 0 & 0 & 0 & 0 \\
\hline $26 / 3 / 2020$ & 1 & 0 & 0 & 0 & 0 & 0 & 0 & 0 & 0 & 0 \\
\hline $31 / 3 / 2020$ & 9 & 1 & 1 & 1 & 1 & 1 & 1 & 1 & 1 & 1 \\
\hline $5 / 4 / 2020$ & 84 & 4 & 3 & 2 & 2 & 2 & 2 & 2 & 2 & 2 \\
\hline $10 / 4 / 2020$ & 725 & 13 & 9 & 4 & 3 & 3 & 3 & 3 & 3 & 3 \\
\hline $17 / 4 / 2020$ & 6,159 & 60 & 38 & 12 & 6 & 4 & 4 & 4 & 4 & 4 \\
\hline $20 / 4 / 2020$ & 6,697 & 115 & 70 & 19 & 8 & 5 & 5 & 5 & 5 & 5 \\
\hline $25 / 4 / 2020$ & 4,975 & 333 & 194 & 42 & 13 & 7 & 6 & 7 & 7 & 6 \\
\hline
\end{tabular}

12 En su declaración sobre COVID-19 del 23 de enero de 2020 la OMS destacó como elemento crítico que el $R_{0}$ del virus se encuentra en el rango de 1.4-2.5. 


\begin{tabular}{|c|c|c|c|c|c|c|c|c|c|c|}
\hline \multicolumn{8}{|c|}{$R_{0}$ efectivo entre $03 / 03 / 2020-16 / 04 / 2020^{*}$} & \multicolumn{3}{|c|}{$\begin{array}{c}\text { Escenarios convergencia a } \\
\qquad R_{0}=1\end{array}$} \\
\hline Fecha & 8.78 & 4.43 & 4.23 & 3.42 & 2.62 & 1.94 & 1.54 & 60 días & 30 días & 15 días \\
\hline $30 / 4 / 2020$ & 3,461 & 915 & 523 & 92 & 23 & 10 & 7 & 9 & 8 & 7 \\
\hline $5 / 5 / 2020$ & 2,393 & 2,172 & 1,301 & 201 & 40 & 14 & 8 & 12 & 10 & 7 \\
\hline $10 / 5 / 2020$ & 1,653 & 3,838 & 2,696 & 428 & 68 & 19 & 10 & 14 & 11 & 7 \\
\hline $15 / 5 / 2020$ & 1,142 & 4,606 & 4,086 & 871 & 117 & 26 & 12 & 18 & 12 & 7 \\
\hline $20 / 5 / 2020$ & 788 & 4,146 & 4,410 & 1,624 & 198 & 37 & 14 & 21 & 12 & 7 \\
\hline $25 / 5 / 2020$ & 544 & 3,252 & 3,807 & 2,607 & 330 & 51 & 17 & 24 & 12 & 7 \\
\hline $30 / 5 / 2020$ & 376 & 2,408 & 2,955 & 3,417 & 540 & 71 & 21 & 27 & 12 & 7 \\
\hline $4 / 6 / 2020$ & 259 & 1,738 & 2,187 & 3,643 & 851 & 98 & 26 & 29 & 12 & 7 \\
\hline $9 / 6 / 2020$ & 179 & 1,239 & 1,583 & 3,321 & 1,274 & 134 & 31 & 31 & 12 & 7 \\
\hline $14 / 6 / 2020$ & 124 & 878 & 1,133 & 2,745 & 1,770 & 184 & 37 & 32 & 12 & 7 \\
\hline $19 / 6 / 2020$ & 85 & 619 & 805 & 2,146 & 2,237 & 249 & 45 & 32 & 12 & 7 \\
\hline $24 / 6 / 2020$ & 59 & 436 & 570 & 1,625 & 2,547 & 335 & 54 & 32 & 12 & 7 \\
\hline $29 / 6 / 2020$ & 41 & 306 & 403 & 1,208 & 2,621 & 445 & 64 & 32 & 12 & 7 \\
\hline $4 / 7 / 2020$ & 28 & 215 & 284 & 888 & 2,477 & 580 & 77 & 32 & 13 & 7 \\
\hline $9 / 7 / 2020$ & 19 & 151 & 200 & 648 & 2,191 & 740 & 92 & 32 & 13 & 7 \\
\hline $14 / 7 / 2020$ & 13 & 106 & 141 & 470 & 1,848 & 919 & 110 & 32 & 13 & 7 \\
\hline $19 / 7 / 2020$ & 9 & 74 & 99 & 340 & 1,507 & 1,104 & 131 & 32 & 13 & 7 \\
\hline $24 / 7 / 2020$ & 6 & 52 & 70 & 246 & 1,200 & 1,279 & 155 & 31 & 13 & 7 \\
\hline $29 / 7 / 2020$ & 4 & 36 & 49 & 177 & 940 & 1,423 & 183 & 31 & 13 & 7 \\
\hline $3 / 8 / 2020$ & 3 & 26 & 34 & 128 & 728 & 1,518 & 215 & 31 & 13 & 7 \\
\hline $8 / 8 / 2020$ & 2 & 18 & 24 & 92 & 559 & 1,554 & 251 & 31 & 13 & 7 \\
\hline $13 / 8 / 2020$ & 1 & 13 & 17 & 66 & 427 & 1,529 & 291 & 31 & 13 & 7 \\
\hline $18 / 8 / 2020$ & 1 & 9 & 12 & 48 & 325 & 1,454 & 335 & 31 & 13 & 7 \\
\hline $23 / 8 / 2020$ & 1 & 6 & 8 & 34 & 246 & 1,340 & 382 & 31 & 13 & 7 \\
\hline $28 / 8 / 2020$ & 0 & 4 & 6 & 25 & 186 & 1,203 & 431 & 30 & 13 & 7 \\
\hline $2 / 9 / 2020$ & 0 & 3 & 4 & 18 & 140 & 1,058 & 482 & 30 & 13 & 7 \\
\hline $7 / 9 / 2020$ & 0 & 2 & 3 & 13 & 106 & 914 & 532 & 30 & 13 & 7 \\
\hline $12 / 9 / 2020$ & 0 & 1 & 2 & 9 & 80 & 778 & 580 & 30 & 13 & 7 \\
\hline $17 / 9 / 2020$ & 0 & 1 & 1 & 7 & 60 & 655 & 624 & 30 & 13 & 7 \\
\hline $22 / 9 / 2020$ & 0 & 1 & 1 & 5 & 45 & 546 & 662 & 29 & 13 & 7 \\
\hline $27 / 9 / 2020$ & 0 & 1 & 1 & 3 & 34 & 452 & 691 & 29 & 13 & 7 \\
\hline
\end{tabular}

Fuente: elaboración propia. *Número reproductivo $\left(R_{0}\right)$ en base a media móvil 5 días estimado al 16 de abril de 2020. 
La tabla también revela la clave de países que han sido exitosos en contener el virus; tal es el caso de China, que no solo logró disminuir sus contagios secundarios a niveles menores de 1.4 en un tiempo reducido ${ }^{13}$, sino que ha sido el país que más tiempo se ha mantenido en estos niveles, en concreto, 54 días consecutivos ${ }^{14}$.

Para evaluar estos resultados en términos del número de infectados en la República Dominicana, en la tabla 3 se presenta la cantidad de contagiados diarios asociados a distintos números reproductivos, al cierre de cada semana laboral durante los últimos 21 días. Se puede apreciar que las políticas de distanciamiento han desacelerado el ritmo de crecimiento de los infectados. De hecho, si las autoridades no hubiesen adoptado las medidas hoy vigentes, cada nuevo infectado hubiese contagiado a alrededor de nueve, llevando la cifra de contagios a poco más de 6.7 millones de personas ${ }^{15}$.

Las cifras anteriores no deben ser subestimadas. A modo de ejemplo, si se considera una tasa de mortalidad de un $2 \%$, equivalente a la inicialmente comunicada por la OMS para COVID-19 ${ }^{16}$, esos resultados suponen haber impedido el fallecimiento de, al menos, 130,000 seres humanos.

Las estimaciones al 16 de abril de 2020 indican que el $R_{0}$ alcanzó 1.54, el mínimo nivel desde que iniciaron las medidas de distanciamiento, aunque todavía superior al umbral de 1 , lo que garantiza la expansión del virus. De mantenerse estas condiciones, el virus se propagaría infectando a un máximo de un $7 \%$ de la población, en tanto su máximo nivel de nuevos contagios semanales ${ }^{17}$ alcanzaría cerca de 51,000 personas hacia septiembre de 2020 , lo que evidencia la necesidad de extender y fortalecer las políticas de distanciamiento social.

13 Se logró tras 23 días de haber implementado medidas.

14 De estos 54 días, 44 estuvieron inferiores a 1.1. Corea del Sur logró este hito durante 5 días.

15 Este escenario implicaba que el virus hubiese infectado un $67 \%$ de la población, resultado consistente con la estimación para República Dominicana del equipo de respuesta del Imperial College London en su Reporte de Impacto Global del COVID-19, en coordinación con la OMS. 16 OMS - Conferencia de prensa sobre COVID-19, 29 de enero de 2020.

17 Esta cifra se refiere a infectados totales, independientemente si se reportan o no. 
Figura 5. Casos de contagios totales para distintos escenarios de $R_{0}$
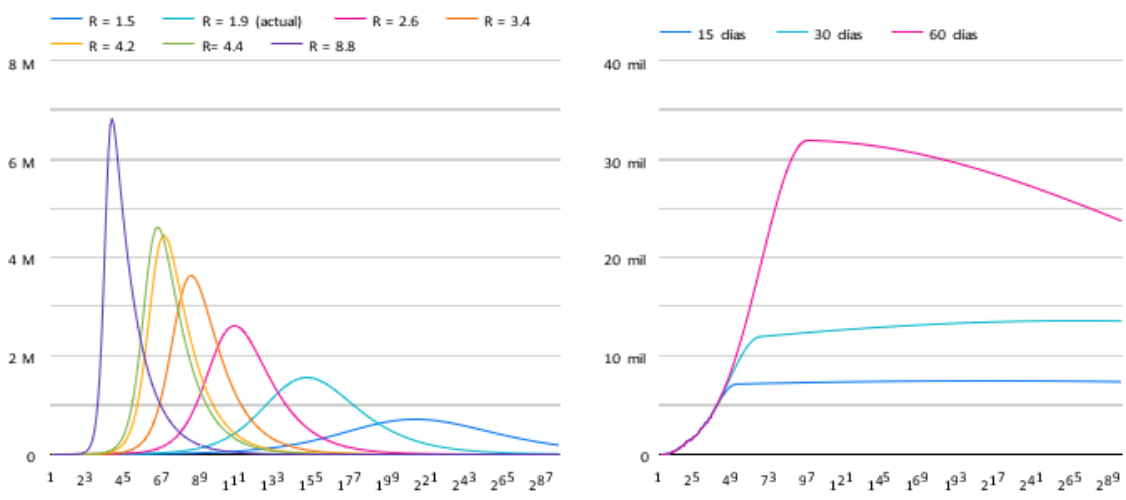

Días transcurridos

Fuente: elaboración propia.

Si tomamos como referencia las efectivas estrategias de contención adoptadas por China y Corea del Sur y lográsemos reducir los contagios secundarios desde los niveles vigentes a valores inferiores a 1.1 en los próximos 60 días, el mayor nivel de infectados rondaría los 32,000 , con un nivel máximo de nuevos contagios semanales cercanos a los 3,200 hacia mediados de mayo. De hacerlo en los próximos 30 días, el máximo nivel de contagios no superaría los 13,500, en tanto el mayor nivel de nuevos infectados semanales ocurriría hacia finales de abril, con un tope rondando los 1,700 casos.

Los resultados para República Dominicana, bajo el contexto de la experiencia internacional evaluada, destacan la importancia del uso del número de contagios secundarios $R_{t}$, como métrica relevante para diagnosticar la evolución de la epidemia.

\section{Conclusiones}

La mitigación del COVID-19 lidera la lista de prioridades de las principales autoridades públicas y privadas a nivel global, debido al impacto humanitario, social y económico que genera una propagación no gestionada adecuadamente. 
En ese contexto, este documento cumple un doble propósito. Primero, contribuye al estudio de la evolución de epidemias, adaptando el enfoque de estado-espacio, usado regularmente en el ámbito de pronósticos econométricos, al modelo epidemiológico canónico (SIR). Dicha adecuación permite capturar la dinámica de los principales parámetros del modelo, tradicionalmente asumidos como constantes, lo que resulta en pronósticos de contagios más realistas.

En segundo lugar, este trabajo se constituye como un marco metodológico útil para los hacedores de política, en tanto permite diagnosticar la evolución de la pandemia en términos de su tamaño final, el momento en que alcanza su pico y bajo cuáles condiciones se disipa, a partir de las políticas de distanciamiento adoptadas.

En ese sentido, aplicando dicho marco al análisis de la evolución del COVID-19 en la República Dominicana y un grupo de países seleccionados, se observa que las políticas de distanciamiento han contribuido a reducir la propagación del virus, lo que se refleja en una tendencia decreciente del número básico de reproducción $R_{0}$, esto es, la cantidad de contagios adicionales que provoca un infectado nuevo ${ }^{18}$.

A nivel global, China y Corea del Sur han sido los países más efectivos conteniendo la propagación, no solo por la rapidez en que redujeron $R_{0}$, sino porque han logrado situarlo alrededor del umbral de 1 , de forma sostenida; en el caso particular de China, durante más de 50 días.

En cuanto a República Dominicana, la caída observada de $R_{0}$, desde nueve contagios secundarios promedio, previo a la adopción de políticas de distanciamiento, a dos contagios, posterior a estas, en tan solo 20 días, supera los declives observados en Francia y Estados Unidos durante el mismo período.

En las próximas semanas, las decisiones que adopten las autoridades, en adición a las conductas que asuma la población, determinarán si la tendencia decreciente observada en el número de contagios secundarios retrocede, aumentando la propagación del virus, o continua su descenso tanto como para aplanar la curva y salvar vidas.

18 Mientras $R_{0}$ supere 1 , la propagación del virus continuará; en caso contrario, la epidemia se disipará. 
De retroceder, las estimaciones hechas al 16 de abril de 2020 señalan que, bajo el escenario en que $R_{0}$ se estabiliza en los niveles actuales, la pandemia se propagaría lo suficiente para contagiar a alrededor del $7 \%$ de la población, con una cifra máxima de nuevos contagios cercana a los 51,000 casos semanales; esto ocurriendo hacia septiembre de 2020.

De continuar su tendencia decreciente y estabilizarse en los próximos 30 días en valores cercanos a 1, tal como ocurre en China y Corea del Sur, el máximo nivel de nuevos contagios rondaría los 13,500; en tanto el mayor nivel de nuevos infectados semanales alcanzaría los 1,700 casos hacia finales de abril de 2020. Estas cifras evidencian la necesidad de extender y fortalecer las medidas vigentes, al igual que destacan la importancia de monitorear el número de contagios secundarios, $R_{t}$ como métrica relevante para diagnosticar la evolución de la epidemia. 


\section{Anexos}

A. Trayectoria de la tasa efectiva de contacto $\left(\beta_{t}\right)$ y número básico de reproducción $R_{0}$ estimados con el modelo estado-espacio (eneroabril de 2020)

Tasa efectiva de contacto Corea del sur $R_{0}$ Corea del sur
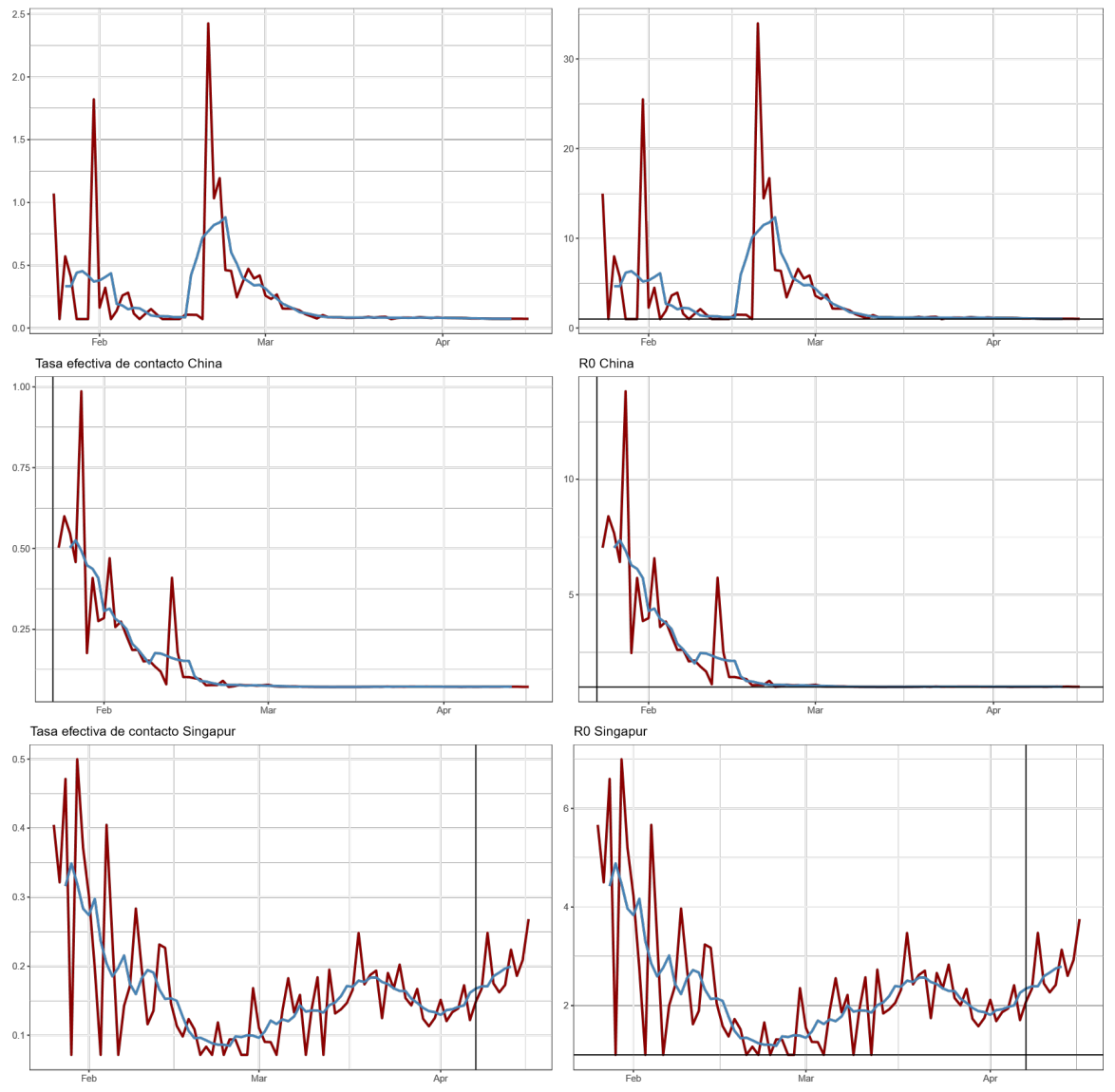

Fuente: elaboración propia. 
Tasa efectiva de contacto Portugal

$$
R_{0} \text { Portugal }
$$
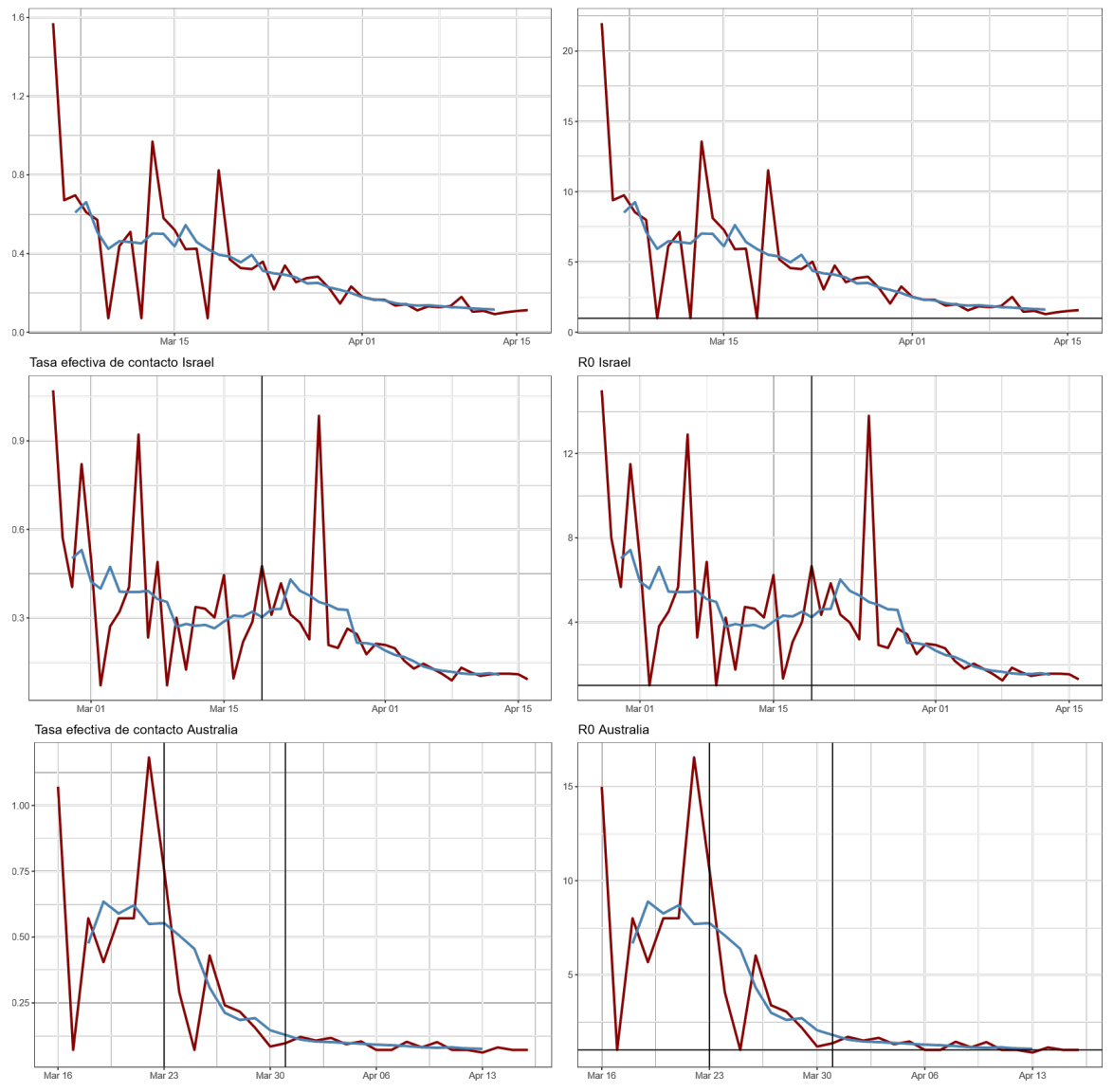

Fuente: elaboración propia. 
Tasa efectiva de contacto Noruega
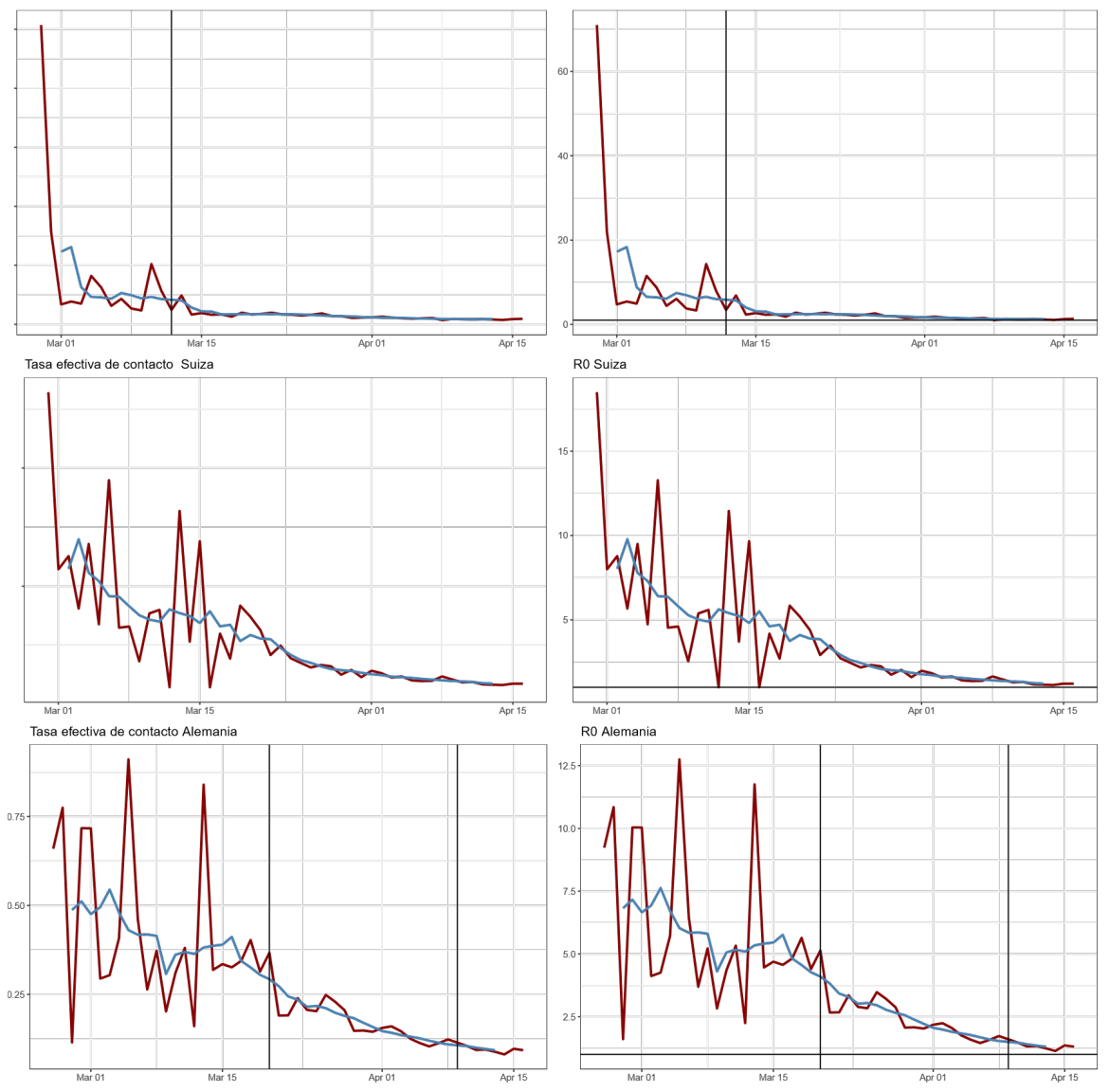

Fuente: elaboración propia. 
Tasa efectiva de contacto Italia

$$
R_{0} \text { Italia }
$$
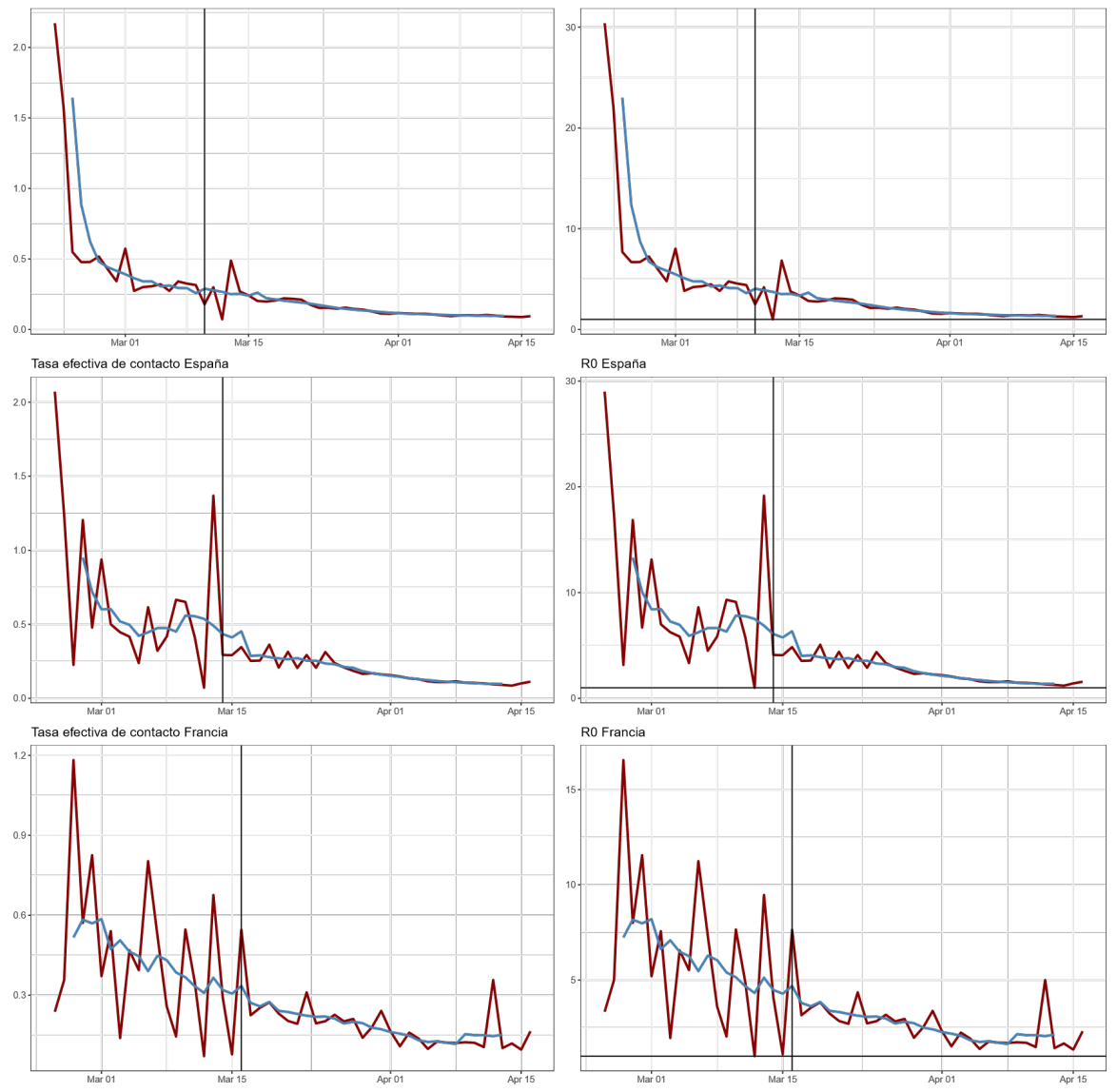

Fuente: elaboración propia. 
Tasa efectiva de contacto Estados Unidos $\quad R_{0}$ Estados Unidos
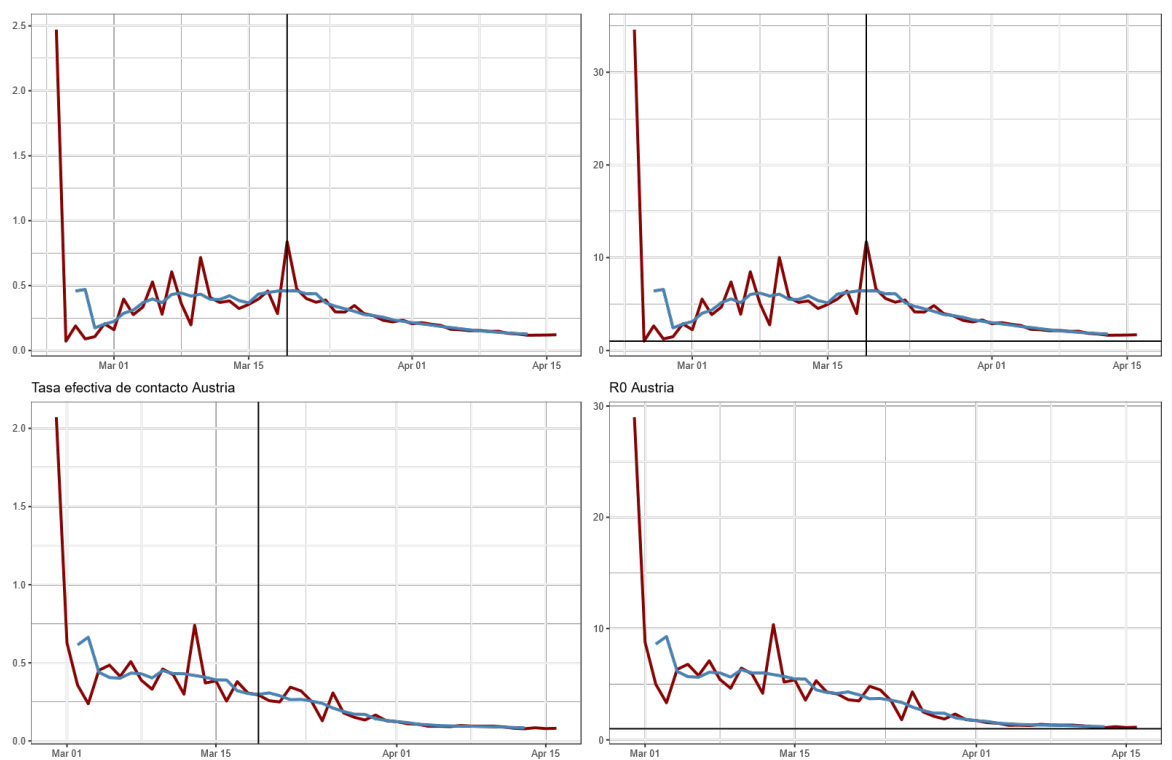

Fuente: elaboración propia.

\section{Referencias}

Sebastian, E. \& Victor, P. (2017). A state space approach for sir epidemic model. International Journal of Difference Equations, 12(1), 79-87.

Eksin, C., Paarporn, K. \& Weitz, J.S. (2019). Systematic biases in disease forecasting-the role of behavior change. Epidemics, 27, 96-105.

Kermack, W. O. \& McKendrick, A. G. (1927). A contribution to the mathematical theory of epidemics. Proceedings of the royal society of london. Series A, Containing papers of a mathematical and physical character, 115(772), 700-721.

De Peña, V. L. \& Ramírez, F. A. (2020). Modelo SIR para el covid-19 en la República Dominicana. Recuperado de https://drive. google.com/file/d/1w3VhRNDZP-vaoiS-sQQNQRPCvre$\mathrm{KFTVh/} \mathrm{view?usp=sharing}$. 
Ross, R. \& Thomson, D. (1910). A case of sleeping sickness studied by precise enumerative methods: regular periodical increase of the parasites disclosed. Proceedings of the Royal Society of London. Series B, Containing Papers of a Biological Character, 82(557), 411-415.

Dietz, K. (1993). The estimation of the basic reproduction number for infectious diseases. Statistical methods in medical research, 2(1), 23-41.

Delamater, P. L, Street, E. J., Leslie, T. F., Yang, T., \& Jacobsen, K. H. (2019). Complexity of the basic reproduction number ( $\mathrm{r} 0)$. Emerging infectious diseases, 25(1), 1.

Liu, Q., Ajelli, M., Aleta, A., Merler, S., Moreno, Y., \& Alessandro Vespignani. (2018). Measurability of the epidemic reproduction number in data-driven contact networks. Proceedings of the National Academy of Sciences, 115(50), 12680-12685. 